\title{
A Strategy of Smart Library Construction in the Future
}

\author{
Duyi He \\ Moro Library, Leshan Normal University, Leshan, China \\ Email: ruihe0406@163.com
}

How to cite this paper: He, D. Y. (2020). A Strategy of Smart Library Construction in the Future. Journal of Service Science and Management, 13, 330-335.

https://doi.org/10.4236/jssm.2020.132021

Received: March 13, 2020

Accepted: April 19, 2020

Published: April 22, 2020

Copyright $(\odot 2020$ by author(s) and Scientific Research Publishing Inc. This work is licensed under the Creative Commons Attribution International License (CC BY 4.0).

http://creativecommons.org/licenses/by/4.0/

\begin{abstract}
Library is going to forward with the development of information technology nowadays, contains Artificial intelligence (AI), 5G in the future, big data, cloudy technology, etc. that are applied in library, a point of view that this is smart library. However, high technology is not able to delegate smart library. In this article, I propose my opinion about smart library from more overall situation, discuss the goal of smart library construction, smart services contain items, analyze the route of realizing smart services, clarify the relationships between services and devices, reader and big data, expound the data center which is the head of a smart library. Proposing the route of construct smart library, in a sense smart library will lead innovative studies.
\end{abstract}

\section{Keywords}

Smart Library, Artificial Intelligence, Database, Library Construction

\section{Introduction}

In the university, knowledge is the key word, the knowledge is the bridge between the staff and students, and hence a university is full with cultures. Library is a crucial position in a university. What is should be for a library and how to get the goal are important issues for a university? In the past, there is a place to keep books, journals and newspapers, etc. in the library. Every reader needs to go to the library if he or she wants to use those resources. However, the situation has taken place great change with information technology development. Nowadays, library has been a high technology platform, such as computer cloudy, artificial intelligence, internet, identification, Robot, 5G, and so on used in library. And then, the way of readers' learning is different with past. So that it is becoming a key issue what should be in the future and how to construct a library. 
Liu Yujing published his research in 2018. It analyzes the information behavior of mobile intelligent terminal users, and discusses the influence on the library construction and development (Liu \& Zhang, 2018). Zhang Tianzi et al. propose their opinion about the development of the university library in the information situation, they consider that the research university library should fit with new information situation in construction, and take research as the core, resource as basement, develop at the four points of resource, service, platform and results, so that serve research and local economic development (Zhao et al., 2018). Artificial intelligence technology develops very fast, and many areas improve efficiency through it. These make analysis about AI how to apply in a library, present AI can help library satisfy the need of the reader through special or individual service (Fu, 2018, Duan, 2020). Liu Wei et al. pose the ten areas application of $5 \mathrm{G}$ in the library, for example no touch borrowing, smart book house, cloudy course, intelligent security, robot service and accurate delivery, etc. (Liu, Chen, \& Zhang, 2019). Dealing with the issue takes place in the present construction of the library, the authors suggest taking three steps to construct library, clear the boundary of theory, pay attention to the integration of technology and service, and build a team of intelligent construction (Xu \& Pan, 2019). Smart library construction becomes a new discussion hot, no matter in information district or library construction. Hence it is not only a hot but also high science technology applications. This way is position at the beginning of terminal, so many hard works are standing the forward place.

In this paper, I propose my opinion about smart library construction. Section 2 discusses the goal and difference between intelligent library and smart library construction. Section 3 gives my protocol how to construct smart library. Section 4 poses construct smart library service platform form system direction. In the last, some conclusions are been given.

\section{Intelligent Library and Smart Library}

Nowadays, many intelligent devices are used in library to improve efficiency. Robot help readers some basement questions, auto-machine can borrow and return books by reader self, intelligent devices cannot change librarian duty but only change the way of our services ( $\mathrm{Fu}, 2018)$. These intelligence devices improve the efficiency of library's services and works, we may name it intelligent library. However, the procedure of intelligent library must be short because of AI high-speed application, so that the development of library will go into smart stage after experience the momentary intelligent procession.

Some literatures pose their opinions about what smart library is. Smart library is a mobile library, it can provide services for readers stride across times and spaces, but the duty of library is not change (Shen, 2019). Smart library should give more special and precise services to readers (Duan, 2020). 5G technology is the best hot one in present, it can provide more services program than before, such as cloudy course, cloudy platform, AV studio and so on (Liu, Chen, 
\& Zhang, 2019). In a word, smart library must base on technology, and the same point is better service. Thus, I propose my strategy about smart library construction from more overall situation, give the main route of construction. In my opinion, smart library not only is a body with high technologies, but also is a smart man, it is able to do some analysis and decisions, and the goal is provide the best services.

\section{A Protocol of Smart Library Construction}

There are many things belong to the duty of the library, but when we back to the original spot, easy to find the best important duty of the library is service for readers. So we can get smart library must provide smart services, it including these characteristics of special, individual, diversify, convenient and quick in serve. we want to realize smart service must through intelligent devices, such as auto borrow machine, reading machine, cloudy, enter read card system, smart book shelf, WIFI, individual serve system, etc. As we know, there are many physical books, journals, newspaper, so we must have the intelligent security system to keep library safe from lost resources and fire. So I propose my scenario of smart library construction include three aspects, intelligent devices, intelligent security and smart services, as shown Figure 1.

Figure 2 shows the common using intelligent devices in the nowadays library, of course there are many new intelligent devices will serve for library in the next days. We collect the big data about reader enter and exit library by intelligent gate system. RFID is a kind of identifiable technology by no touch object, we assign RFID number for each physical resources, so that convenient to manage it. As intelligent bookshelf is important spot to smart library, its function is shown Figure 3. Each bookshelf is the bottom of book information management, the main duty of it is manage this shelf books, and provide special information for the reader, if some books' position are wrong, it can correct it by its arm. At the same time, it is also a platform of exchange with readers, help them find the books they wanted easily. Bookshelf exchanges with information Centre through level-hub, construct information net in the library.

Service is the goal of library, smart service is make readers feel better via smart technology. Sum in all, smart services include serve students, staff, community readers, disabled people, local economic development and collection keep record. It is shown as Figure 4.

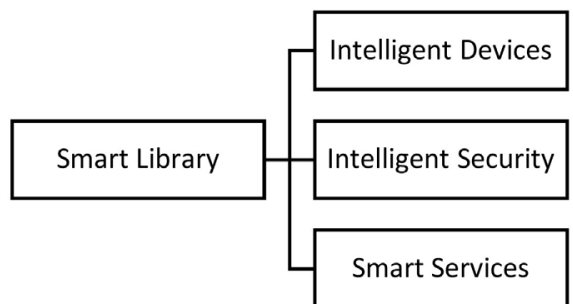

Figure 1. The main contents of the smart library in simply. 


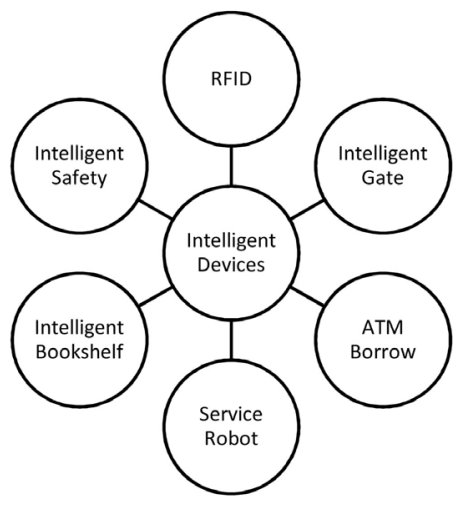

Figure 2. The common intelligent devices.

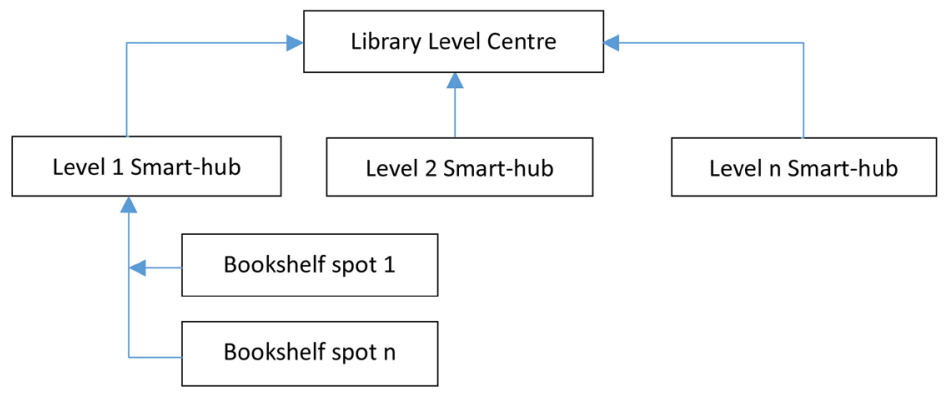

Figure 3. The smart library level bookshelf information system chart.

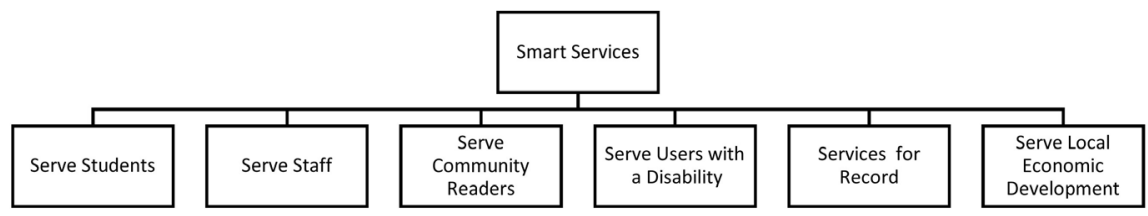

Figure 4. The items of smart services in the smart library.

\section{The Head of Smart Library Construction}

\subsection{Data Centre Construction}

The head of smart library is the database, including library document, such as books, journals, e-book, e-journal, e-resources, etc. and service for target information resources, such as library members' information, university achieves, recordkeeping, collections. All of the services in the library are based on databases, so we need construct more perfect data resources.

In Figure 5, we show the relationship among the serve object, devices, services and database. A library provides services for readers by intelligent devices visit all kinds of database. If there is no database the devices will lost their function of service. Hence, it is the key point how to construct perfect data center of the library. How to construct a big data center we give our scenario as shown Figure 6. We may divide data center into four parts, physical big data, e-resource data, reader information data and special data according to the duty of a library. That is we know what we have, who are the object needing services, what are their requirements, and we how to provide. The answer for these questions is the 


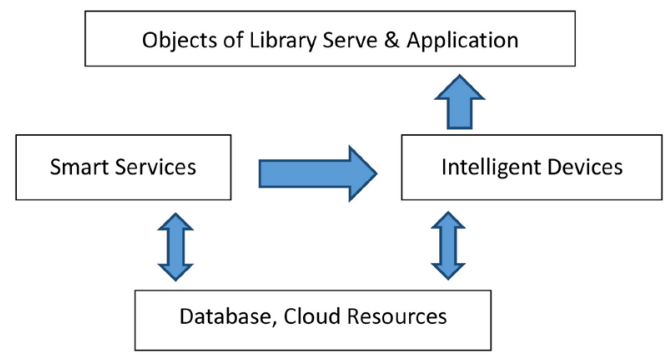

Figure 5. The relationship among the object, intelligent devices, smart services and database.

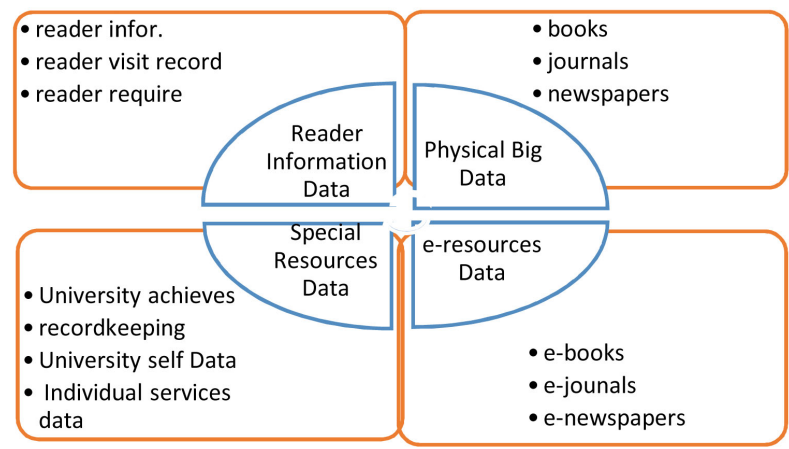

Figure 6. The diagram consists of smart library data center.

route of construction data center. We can fulfil a database both through artificial and intelligent devices four each. For example, we can add a book into the physical big data by manual work, or by scanning its RFID.

\subsection{Interface System Construction}

In Figure 7, we give the chart among the reader, data center and interface system. Obviously interface system is the bridge between the reader and data center. Library provides services through interface system. The system manages the data center, which is the head of the smart library, and gets the useful data deliver to the reader who needs it.

Of course, smart library needs others manage system to keep safety, such as intelligent gate system, fire alarm system, avoid book lose system, and staff work system. All of these system must integrate into one manage system to obtain the best efficiency. It is the best important that interface system is able to analysis requires and make some decisions, that's mean smart.

\section{Conclusion}

Smart library is the direction of library development in the future, to deal with some issues about intelligent library and smart library, I pose my think of it after analyzing the situation of libraries. These libraries just equipped with intelligent devices can be named the intelligent library not a smart library. When a library not only is a body with high technologies, but also is a smart man, it is able to do some analysis and decisions, and the goal is provide the best service. It should be 


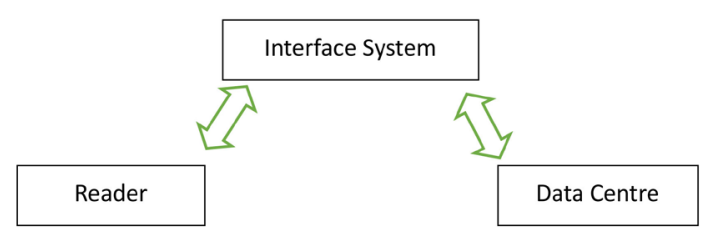

Figure 7. The diagram of the interface system function.

smart library. Hence the smart library also needs library hardware and soft system support, which is the route of realizing smart services. Hardware and software are both important in the procedure of construction. Clarifying the relationship between services and devices is services based on devices. Reader can be enjoying smart services through the interface system visit database. Thus data center is the head of a smart library. I suggest that constructing a smart library should insist do well these aspects, database construction, intelligent devices utilizing, management and interface system development. Last but not the least is every librarian must know that all of devices and systems are only used to help us provide better services, our duty is our duty, improving staff skills and think is truth forever.

\section{Acknowledgements}

This research was financially supported by the Sichuan Education Department Foundation (No. 18ZB0273) and Leshan Science and Technology Bureau Foundation (No. 19NZD100, Duyi He).

\section{Conflicts of Interest}

The author declares no conflicts of interest regarding the publication of this paper.

\section{References}

Duan, H. (2020). Research on the Development Strategy and Smart Service of Samrt Library Construction: Taking the Library of Shaanxi Polytechnic Institute as an Example. Wireless Internet Technology, No. 1, 96-97.

Fu, Y. X. (2018). Research on Application of Artificial Intelligence in Library Construction. Library Work and Study, No. 9, 49-50.

Liu, W., Chen, C., \& Zhang, L. (2019). 5G and Smart Library Construction. Journal of Library Science in China, 45, 51-53.

Liu, Y. J., \& Zhang, X. Q. (2018). Characteristics of Mobile Intelligence Terminal Users Information Behavior and Its Impact on Library Construction and Development. Information and Documentation Services, No. 4, 89-94.

Shen, L. P. (2019). The Think of Smart Library Construction. The Library Journal of Henan, 39, 7-9.

Xu, L., \& Pan, X.-X. (2019). The Thinking about Technology and Service in the Construction of Smart Library. Journal of the Library Science of Sichuan, 228, 10-14.

Zhao, T. Z., Zhang, X. M., Jing, M. C., \& Guan, X. (2018). Development of the Research Library in the New Information Environment. Library Information Research, No. 3, $36-41$. 